\title{
REESTUDO DE ALGUNS TIPOS DE ABELHAS NEOTROPICAIS DESCRITOS POR FRIESE E CONSERVADOS NO MUSEU DE BERLIM (APOIDEA, COLLETIDAE, ANTHOPHORIDAE) ${ }^{1}$
}

\author{
Jesus S. Moure ${ }^{2}$
}

\begin{abstract}
REFSTUDY OF SOME TYPE. SPE:CIMENS OF NEOTROPICAI BEES, DESCRIBIDD

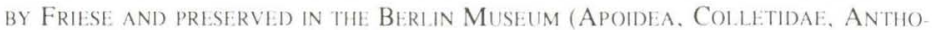
PHORIDAE). Among the specimens of Neotropical Bees described by Friese and preserved in the Berlim Museum the following ones were studied, or synonymized. or to some of them given a new status and redescribed. namely: the specimen of Megacilissa pretiosa Friese. 1898. is considered the holotype of Ptiloglossa pretiosa. Ptilothrix ? similis Friese. 1899 is a synonym of Melitoma nudipes (Burmeister. 1876). Centris (Epicharis) prgialis Friese. 1899, is an independent species, the present specimen the holotype and Bahia the type locality. Centris (Epicharis) flava Friese, 190() a widely distributed species in South and Central America. described from 'Brasilia' is also considered as an independent species. The specimen of Centris atra Friese, 1900, from San Antonio. Colombia, is Centris (Melacentris) aeneiventris Mocsáry, 1899 and the specimen from Blumenau (Rio das Antas). SC, Brazil. at the Viena Museum. is the melanic form of Centris (Melacentris) dorsata Lepeletier. 1841, the true Centris atra Friese, 1900), belongs in the subgenus Ptilotopus Klug. 1810, and is recorded from Northern South Anerica to Central Brazil [North of the States of Minas Gerais and Goiás]. Centris xylocopoides Fox. 1899, from Trinidad. confounded with $C$. atra belongs to Melacentris and compared with the type of Centris (Melacentris) braccata Packard, 1869. proved to be a synonym. Centris ruficauda Friese, 1900) is the melanic form of Centris (Melacentris) intermixta Friese. 190(). Because Centris atra, selected by Sandhouse as the type species of Melanocentris. is a Ptilotopus, and the type species of Ptilotopus Klug. 1810. - Ptilotopus americanus Klug, 1810 - was included by Friese among his Melanocentris. Melacentris new name is proposed for Melanocentris autorum, non Friese, 1900), with Centris dorsata Lepeletier, 1841, as the type species.

KEY WORDS. Anthophoridae, Colletidae. Neotropical, systematics, synonymy
\end{abstract}

Entre os espécimens de abelhas neotropicais descritos por Friese e recebidos do Museu de Berlim para estudo, vieram alguns exemplares representando tipos de algumas espécies, de difícil reconhecimento, e outros que, apesar de não serem tipos, figuravam na coleção Friese como material de comparação na interpretação das suas espécies. Algumas foram trocadas de gênero ou de 'status', outras sinonimizadas e particular atenção mereceu a designação de Centris (Ptilotopus) atra, por Sandhouse como espécie tipo de Melanocentris. Por essa designação,

1) Contribuição número 817 do Departamento de Zoologia. Universidade Federal do Paraná

2) Departamento de Zoologia. Universidade Federal do Paraná. Caixa Postal 19()20), 81531-990) Curitiba, Paraná, Brasil. Bolsista do CNPy. Processo 305585/76. 
Melanocentris passou para a sinonímia de Ptilotopus tornando necessário criar um nome novo - Melacentris - para Melanocentris Autorum, non Friese, 1900, tendo como espécie tipo Centris dorsata Lepeletier, 1841, preservando esse grande grupo de espécies dentro do conceito atual.

Nota: Nas descrições abaixo, as medidas citadas entre parênteses são dadas em centésimos de milímetro.

\section{Ptiloglossa pretiosa (Friese, 1898)}

Megacilissa pretiosa Friese, 1898. Ann. k.k. Naturhist. Hofmus. 13 (1): 67. 6.

É aparentemente o tipo, embora não conste como tal na coleção Friese no Museu Zoológico da Universidade de Humboldt, Berlim. Este exemplar leva o n ${ }^{\circ}$ "3/6 Ptiloglossa pretiosa $=1$ Ex. (keine Typen)" na lista de empréstimo 41/91. Considero-o, entretanto, como possível tipo, tendo em vista a afirmativa de Friese no final da descrição: "Megacilissa pretiosa liegt mir in 19 aus Brasilien vor." Pelo alto valor, por ter ficado na coleção Friese, refletindo seu conceito para a espécie, faço alguns comentários sobre o mesmo.

O exemplar está em bom estado de preservação, faltando apenas o artículo ungueal do tarso direito. A etiqueta de procedência é um tanto estranha. Impresso: " Brasil/ S. Leopoldo / 1896" e, à tinta, "Cuba", sobre o provável nome do coletor. São Leopoldo fica no Estado do Rio Grande do Sul, próxima à Porto Alegre, a uma altitude de $15 \mathrm{~m}$ sobre o nível do mar. A referência que acompanha a descrição da espécie diz apenas ser um exemplar $\$$ do BRASIL.

Talvez a duplicidade na etiqueta de procedência no exemplar tenha levado a direção do Museu a não considerá-lo como tipo. A espécie ocorre em todo o Sul do Brasil (MOURE 1945: 169, Est. XV).

A diagnose é curta e não muito esclarecedora para uma fêmea de Ptiloglossa: " $\mathbf{9}$. Nigra, ut tomentosa, abdomine viridi-coeruleo, metathorace segmentoque 1. autem albido-pilosis, 2.-4. marginibus albido-ciliatis, 5.-6. fusco pilosis." Seguida por mais alguns pequenos esclarecimentos complementares: "Megacilissa pretiosa ähnelt der tomentosa, doch ist das Abdominalsegment I und der Metathorax lang weisslich behaart, Segment 2-4 nur am Endrande schmal weisslich gefranst, auch der Bauch weisslich behaart."

As minhas notas:

Fêmea: Comprimento total aproximado $13,0 \mathrm{~mm}$, da asa anterior $11,7 \mathrm{~mm}$; largura da cabeça $5,33 \mathrm{~mm}$ e do segundo tergo $7,25 \mathrm{~mm}$.

Preta; os tergos de um verde-azul-aço; as tíbias posteriores escuro-ferrugíneas.

Pilosidade predominante preto-murina (isto é, pêlos fuscos, mais claros para a base); com algo de branco-cremoso na face à volta do clípeo, nas genas inferiormente, nos lados do pronoto, no metanoto, propódeo e base do primeiro tergo, em todo lado ventral do abdômen, nos fêmures médios e posteriores e na metade anterior da escopa tibial; na porção distal do primeiro tergo e nos seguintes de um murino-escuro; nas margens dos tergos segundo ao quarto com faixa 
marginal delicada de pêlos brancos, nos lados sobressaindo ao bordo apical. A pilosidade murino-escura dos tergos relativamente rala, deixando ver o tegumento. Nos primeiros esternos branca, bastante longa e plumosa, nos últimos menos desenvolvida e um pouco mais fusca, dando grande destaque a dois tufos de pêlos esbranquiçados bastante longos na dobra ventral dos tergos terceiro e quarto.

Superficie do clípeo irregular com pontuação bastante esparsa, os intervalos micro-reticulados de 3-4 diâmetros de ponto e no disco superior quase nula; o labro liso com um grande mamelão discal deprimido ou sulcado ao longo do meio.

Órbitas bastante convergentes em cima, com a interorbital superior cerca de cinco sétimos do comprimento do olho; distância interocelar apenas 1,2 vezes o diâmetro do ocelo médio e a ocelorbital pouco mais de cinco sétimos desse diâmetro.

As buscas desta espécie deveriam concentrar-se na baixada litoral do Rio Grande do Sul. A descoberta de ninhos e observação do comportamento são cruciais para a associação dos sexos e para sua perfeita sistematização.

Aparentemente pode separar-se de Ptiloglossa matutina (Schrottky, 1904). Veja-se a comparação feita por Schrottky (1907: 11-12) entre $P$. eximia e $P$. matutina.

\section{Melitoma nudipes (Burmeister, 1876)}

Centris nudipes Burmeister, 1876. Stett. ent. Zeit. 37: 165. - Dalla Torre, 1896. Cat. Hymenopt. 10: 307. - Friese. 1900). Ann. k.k. Naturhist. Hofmus. 15: 297. 76.

Ptilothrix ? similis Friese, 1899. Ann. k.k. Naturhist. Hofmus. 14: 272. 3. - Schrottky, 1902. Revta

Mus. Paulista 5: 535, 2, - Strand. 1909. Deutsch. ent. Zeitschr.: 230. - Strand, 1910. Zool.

Jahrb. Abt. Syst. 29: 510, 62.

Meliphila nudipes: Schrottky, 1902. An. Mus. Nac. Buenos Aires 7: 325, 2. - Schrottky, 1903. An.

Soc. Cient. Argentina 55: 183.

Ptilothrix nudipes; Friese, 19()4. Zeitschr. f. Syst. Hymenopt. Dipt. 4: 100).

Melitoma nudipes; Brèthes, 1909. An. Mus. Nac. Buenos Aires 19: 253. - Schrottky, 1913. An. Soc.

Cient. Argentina 75: 255 - Bertoni, 1918. An. Cient. Paraguayos 2 (3): 221.

O holótipo fêmea de Ptilothrix ? similis está em perfeito estado de conservação. Na etiqueta de procedência consta: "Brasil/ Curitiba/ 1897/ Schenk". $\mathrm{Na}$ de determinação, 1898, falta o sinal "?", justificado pelos comentários à descrição.

A diagnose latina de Centris nudipes por Burmeister, em 1876, é extremamente breve: "Fusco-nigra; capite thoraceque cinereo- hirtis; pedibus 4 anticis subnudis; postice feminae hirsutis, maris incrassatis. Long. 4 1/2 lin. (10mm.)". Os exemplares foram coletados pelo mesmo Burmeister na bacia do Paraná, em Entrerios, Argentina. "Bei Paraná in Entrerios von mir gesammelt."

Friese, diz em 1900, desconhecer a espécie, não tendo encontrado os tipos no Museu de Halle: "Mir unbekannt geblieben. Nicht in Mus. Halle." Vários tipos de Burmeister encontram-se no Museo Nacional de História Natural de Buenos Aires.

A sinonímia foi reconhecida por Friese em 1904, com o seguinte comen- 
tário: "Meliphila nudipes Burm. =Ptilothrix similis Friese (sec. spec. typ.), sodass diese Art jetzt heissen muss = Ptilothrix nudipes Burm." Engano talvez devido ao trabalho de Schrottky, (1902a) pois Burmeister a descreveu em Centris.

Nunca encontrei esta espécie em Curitiba porém tenho exemplares de Barranco Branco (Mato Grosso, BRASIL), comparados em 1953 com os tipos de Burmeister, devido à amabilidade do Dr. R. Orfila. Sua distribuição parece confinada à Bacia Média e Alta do Paraná.

A correção para Melitoma é devida a Brèthes (1909) em um longo trabalho sobre Himenópteros do Paraguay. O título correto seria "Hymenoptera Paraguayensia".

Apesar dos trabalhos de Friese e Brèthes reconhecendo a espécie de Friese como sinônimo da espécie de Burmeister, Strand, 1910, ainda a cita como de Friese (1909: 230 e 1910: 510).

A retirada desta espécie do gênero Ptilothrix está justificada pela presença de arólios bem desenvolvidos.

Resolvido o problema de sua colocação sistemática, a espécie é facilmente reconhecível pelas descrições de Burmeister e Friese. Dou uma complementação da mesma, com o tipo em mãos.

Holótipo fêmea. Comprimento total aproximado $10,4 \mathrm{~mm}$, da asa anterior, desde o ápice do esclerito costal ao ápice da asa, 7,92 $\mathrm{mm}$; largura da cabeça $3,6 \mathrm{~mm}$ e do segundo tergo $9,33 \mathrm{~mm}$.

Pardo-escura; antenas fulvo-ferrugíneo-claras.

Pilosidade geral da cabeça pálida; branca no labro, clípeo, paroculares inferiores, genas, metanoto e flancos do propódeo; ligeiramente fulva do clípeo para cima; o fulvo mais definido no mesoscuto e escutelo; fracamente pardoocrácea nos meso- e metepisternos. Nos tergos as depressões marginais glabras e lisas, mais largamente no primeiro e diminuindo rapidamente até o terceiro; a base das depressões pontuado-pilosas, mais largamente para os lados. Na base do primeiro tergo esbranquiçada, preta do segundo ao quinto, com manchas evidentes formadas por pêlos brancos nas extremidades da margem do segundo tergo, nos demais apenas vestigiais; a fímbria prepigidial parda passando à branca nos lados . Nos esternos pardacenta porém esbranquiçada lateralmente. Escopa tíbio-tarsal pardo-escura.

Olhos pouco mais longos de duas vezes sua largura (232: 112); órbitas internas fraca e suavemente emarginadas, com a distância interorbital máxima menor que o comprimento do olho (210: 220: 200); genas, de perfil, muito mais estreitas que o olho (40); malar linear (3); clípeo pouco abaulado, quase duas vezes mais largo que longo e seu comprimento ligeiramente menor que a distância ao ocelo médio (100: 190: 105); palpos labiais em repouso atingindo as coxas posteriores (460); distância interalveolar quase cinco vezes o diâmetro do alvéolo, este pouco menor que a distância alveolorbital (110:30: 100: d24); interocelar 2,2 vezes o diâmetro do ocelo médio, a ocelorbital cerca de 1,7 vezes (70: 44: 54: d32). Escapo claramente mais curto que a alveolocelar, quase três vezes seu diâmetro, cerca de dois sétimos da soma do flagelo e pedicelo (70:24:244), mais

Revta bras. Zool. 12 (4): 939 - 951, 1995 
curto que os três primeiros flagelômeros juntos; flagelômero basal pedunculado, duas vezes seu diâmetro apical, mais longo que os três seguintes juntos, o segundo menos da metade de seu diâmetro e os seguintes subiguais, bem mais curtos que o próprio diâmetro (50: 10: 18: 18: d24). Arólios bem desenvolvidos.

Pela combinação da cor do tegumento e da pilosidade Melitoma nudipes pode ser facilmente reconhecida entre todas as espécies de Melitoma Neotropicais. Note-se particularmente a falta ou redução das faixas marginais nos tergos, restando apenas vestígios no segundo tergo.

\section{Epicharis (Epicharis) pygialis (Friese, 1900)}

Centris (Epicharis) rustica var. pygialis Friese, 1900. Ann. k.k. Naturhist. Hofmus. 15 (3-4): 254.

Na lista de empréstimo enviada pelo Museu de Berlim diz: "538/4 Epicharis pygialis=1 Ex. (keine Typen)".

Pelas razões abaixo apresentadas considero-o como provável holótipo da espécie. Tem as seguintes etiquetas: De cor verde, com uma linha preta em cima e uma pontuada incompleta embaixo: /Montevideo/, manuscrita, um pouco borrada no final "deo"; uma segunda etiqueta verde sub-quadrada: /Montevideo/ oder/Bahia/; segue-se a etiqueta de determinação de Friese, de cor branca, com os dizeres manuscritos: /Epich. rustica/ v. pygialis $n$. var./ e impresso no final "det. Friese 1898"/.

É uma boa espécie, e não simples variedade, da Amazônia e BrASIL Central. Está representada na coleção Moure (DZUP) por exemplares de Iquitos, Loreto, PERU, e no Brasil: Tabatinga, Manacapurú, São Gabriel (no Rio Negro), Sto. Antônio do Içá e Rio Parauary, no Amazonas; Faro e Óbidos, no Pará; Serra do Navio, no Amapá; e Marlieria, Minas Gerais, "Parque Forestal do Rio Doce". Esta última localidade torna mais provável ser a procedência do tipo "Bahia" e não "Montevideo".

A descrição apesar de extremamente breve trás o essencial para o reconhecimento da espécie: "Var. 9. Abdomenende (3-6) roth gefärbt, oben etwas glatter und glänzender, Nebengesicht mit kleinem gelbem Punkt, 20-21 mm. lang.pvgialis n.var., Bahia, Montevideo (Mus. Berlin)." e, mais adiante, nos comentários: "liegen mir von pygialis nur 2 9 von Bahia und Montevideo (Mus. Berlin) vor." Evidentemente houve uma "composição" ou mesmo um 'lapsus calami' de Friese, falando de "dois" exemplares fêmeas, um da Bahia e outro de Montevideo, sendo que o que realmente existe é um único exemplar com duas etiquetas. Por isto considero este exemplar como o holótipo de Epicharis (Epicharis) pygialis Friese, 1900 .

As principais medidas do tipo são: Comprimento total aproximado $21,7 \mathrm{~mm}$, da asa anterior 13,3 mm; largura da cabeça $6,08 \mathrm{~mm}$ e do segundo tergo abdominal $7,15 \mathrm{~mm}$. Comprimento do olho (360); das interorbitais, divergentes para baixo (265: 308: 320); clípeo tão longo como cerca de 7/9 da sua largura e quase igualando sua distância ao bordo inferior do ocelo médio (185: 240: 180); distância interalveolar mais de duas vezes a alveolorbital, esta igual ao diâmetro do alvéolo 
e, do bordo superior do alvéolo ao inferior do ocelo lateral três diâmetros (120: 50: d50: 150); distância interocelar duas vezes o diâmetro do ocelo médio e um pouco mais curta que a ocelorbital (60: 74: d30); pouco mais de um diâmetro a distância ocelocipital (50); comprimento do escapo 1,7 vezes seu diâmetro, cerca de um sexto do comprimento do flagelo e pedicelo juntos, mais longo que a distância alveolocelar; flagelômero basal pouco mais curto que o escapo, pedunculado, mais longo que os dois seguintes juntos (26: 44), o terceiro flagelômero ligeiramente maior que seu diâmetro.

No disco do clípeo, os pontos do terço superior grossos (até 60 micra), os intervalos lisos em carenas imperfeitamente delimitadas; ao longo do meio um pouco deprimido, brilhante, com alguns pontos menores (30-40 micra); no terço apical com poucos pontos (40 micra) com intervalos de 4-6 diâmetros de ponto e com micro-pontos intercalados, a superfície, em luz lateral, longitudinalmente micro-rugulosa, um pouco irregular. (Nos exemplares da Amazônia as microrogulosidades longitudinais mais fracas e mais finas, mais laterais, deixando o disco muito mais liso; os pontos no terço basal um pouco menores, entre 40 e 50 micra, os intervalos mais planos igualando ou superando o tamanho dos pontos e no terço apical os micro-pontos mais escassos).

\section{Epicharis (Epicharis) flava Friese, 1900}

Epicharis rustica var. flava Friese, 1900). Ann. k.k. Naturhist. Hofmus. 15: 254

A seguir, nesse mesmo trabalho, Friese descreve como variedade flava, de "Brasilia" (BRASIL), sem localidade definida. Trata-se de uma boa espécie, convivendo em grandes áreas com E. rustica e E. pygialis.

A distribuição de rustica e flava é enorme. A de flava excede no Norte e no Sul os limites de rustica. Ví exemplares determinados por Friese no Museu de Paris. Tenho exemplares desde Costa Rica até o Sul do Brasil, Norte da Argentina e Paraguai.

Estas três espécies se separam facilmente pela seguinte chave:

1. Últimos segmentos do abdômen avermelhados, no terceiro tergo as manchas avermelhadas menores que o restante, pardo-escuro; com uma pequena estria amarela, estreita, na extremidade inferior das áreas paroculares . . . . pygialis

- Abdômen inteiramente preto, ou pardo escuro; áreas paroculares inteiramente

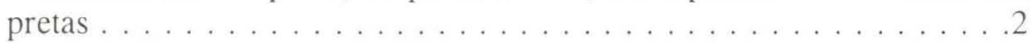

2. Tórax dorsalmente um pouco grisalho-piloso pela mistura de pêlos pretos e brancos; esterno, episternos, propódeo e também a base do primeiro tergo branco-pilosos .......................... flava

- Tórax, propódeo e base do primeiro tergo inteiramente preto-pilosos, com alguns pêlos brancos misturados no mesoscuto mais raramente nos lados do tórax. Maiores. . . . . . . . . . . . . . . . . . . . rustica 


\section{Centris (Ptilotopus) atra Friese, 1900}

Centris atra Friese, 1900. Termész. Füz. 23: 41. - Friese, 1900). Termész. Füz. 23: 118.

Centris atra; Friese, 1900. Ann. k.k. Naturhist. Hofmus. 15 (3-4): 267. 26 e 344. 4. (partim).

A lista de empréstimo diz: "537/3 Centris atra=1 Ex. (keine Typen)".

O exemplar é de S. Antônio, Colômbia, determinado como "atra", porém com uma nota "Arbeitetikett bitte an der Nadel lassen".

Certamente não é o tipo de $C$. atra, pois não corresponde à descrição da espécie. Diz a curta diagnose em latim: "Atra, nigro-hirta, clypeo glabro nitidoque, lateribus punctis nonnullis, scutello bigibboso, scopa atra." seguido de: "C. atra ist die grösste Form unter den ganz schwarzen und dadurch leicht kenntlich." Este mesmo carácter "scutello bigibboso" é destacado em chave para outras espécies. Realmente é uma das sinapomorfias de Ptilotopus além da conformação das mandíbulas, placas basitibial e pigidial, e genitália do macho.

A descrição é taxativa num ponto: "scutello bigibboso", e mais abaixo, com mais detalhe: "Thorax sparsam und grob punktirt, die beiden Höcker des Scutellum liegen dicht bei einander und sind gewöhnlich unbehaart." Também na chave que precede as descrições consta na segunda parte do dilema 3 "Scutellum zweihökerig, grosses Thier, 25mm. lang 26. atra Friese, Columb., Brasil", e ao descrever o macho novamente destaca: "Scutellum zweibeulig, glatt und glänzend. 22,5mm. lang. $1 \sigma^{\prime}$ von Venezuela (S. Parime); 2 q auch von Columbia."

Apesar de toda essa facilidade no reconhecimento da espécie, proclamada pelo autor, o mesmo Friese cometeu engano na identificação de vários exemplares, criando uma confusão em torno do seu real significado.

Ao exemplar em mãos, de S. Antônio, Colômbia, não se aplica a descrição. O escutelo está todo empastado, mas é inteiramente piloso e não se destacam os tubérculos lisos e alongados com que Friese caracteriza a espécie.

No Museu de Viena ví um dos exemplares de Blumenau (Ribeirão das Antas), Virgil 1896 e que também não corresponde à espécie definida, tratando-se da forma melânica de $C$. dorsata Lepeletier, 1841. A invasão do mesonoto de $C$. dorsata pela pilosidade preta é comum em exemplares do litoral de São Paulo, Paraná e Santa Catarina. O Prof. S. Laroca coletou em Alexandra e Antonina (Paraná), com certa frequência esta espécie, com melanismo variável, visitando flores de "Cassia", provavelmente Senna multijuga var. multijuga (L.C. Richard), uma Cesalpinacea, segundo o Prof. O. Guimarães.

O subgênero foi interpretado pelos melissólogos posteriores com base nas características desta última espécie: dorsata. Por esse motivo a escolhí como espécie tipo para o nome abaixo proposto.

Tenho exemplares da verdadeira $C$. (Ptilotopus) atra vindos do Norte de Goiás e também do Norte de Minas Gerais. Na Coleção Campos Seabra (MNRJ) há fêmeas coletados em Minaçú, altitude $315 \mathrm{~m}$, no vale do rio Tocantins no extremo Norte de Goiás. De acordo com os dados de Friese chega até Colômbia e Venezuela.

Por Centris atra ter sido designada por SANDHOUSE (1943: 569) espécie 
tipo de Melanocentris, este subgênero passa a ser um sinônimo de Ptilotopus, Ptilotopus americanus Klug, 1810 (monobásico) e não americanorum usado por LePELETIER (1825: 239) e também por SANDHOUSE (1943: 595). LePELETIER (1841) descreveu esta espécié como nova, e tive ocasião de estudar o tipo no Instituto Zoológico da Universidade de Turim. Corresponde à espécie descrita por Klug em 1810. Como curiosidade anoto que as duas primeiras espécies descritas por Lepeletier (2: 150) pertencem a Ptilotopus, a saber: Centris denudans e Centris derasa!

Pela inclusão da espécie tipo de Ptilotopus entre as espécies de Melanocentris, sem nenhuma conotação especial nem designação de espécie tipo para Melanocentris, esta designação já havia nascido errada. O procedimento de Friese realmente invalidara Ptilotopus ao colocá-lo na sinonímia de Centris na listagem do início da Monografia (pag. 237).

Ptilotopus foi restaurado novamente como gênero por Snelling (1984:48). Se o procedimento de Snelling fosse atendido, creio que todas as outras designações subgenéricas deviam sofrer o mesmo tratamento. É a eterna discordância entre os sistematas sobre quando se deve considerar um grupo como gênero ou subgênero.

Na segunda edição dos Principles of Systematic Zoology (E. Mayer \& Peter D. Ashlock, 1981: Glossary: p. 417) há a seguinte definição: "Genus (pl. genera). A category for a taxon that includes one species or a group of species, presumably of common phylogenetic origin, which is separated from related similar units (genera) by a decided gap: the size of the gap is in inverse ratio to the size of the unit." O grifo é nosso. Como não há definição do que se entende por "gap", considero como gênero todo táxon natural (grupo de espécies ligadas genealogicamente) que possui ao menos uma sinapomorfia a separá-lo de outros táxons naturais. Para a montagem dos grupos ('táxons') e descoberta dos níveis de posicionamento seguem-se "normas de processamento clássico ou numérico = Taxonomia", das quais resulta "a hierarquia justificada entre os táxons = Sistemática". Mantendo-se o significado original da terminologia, evitar-se-ia a presente confusão existente no uso dessas palavras.

Torna-se, portanto, necessário propor um nome novo para este importante e numeroso grupo de Centridini, sem mudar seu sentido. Por isso escolho um nome

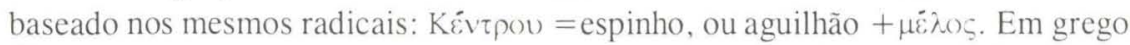
Centron é um nome neutro e o nome corretamente formado Melacentron. Entretanto, o nome foi consagrado por FABRICIUS (1804), como feminino e assim usado subseqüentemente. O subgênero criado por Friese simplificado para Melanocentris deveria ser escrito ae. O que agora proponho sai com defeito para mantê-lo como feminino, mas altamente conveniente por assemelhar-se ao anterior, diferindo o suficiente para não confundi-los: 


\section{Centris (Melacentris), subg.n.}

Centris (Melanocentris): autorum. non Friese, 1900.

Espécie tipo: Centris dorsata Lepeletier, 1841.

O grupo foi definido sumariamente por Friese (1900: 244): "I. Abdomen schwarz ... Melanocentris n. subgen."

A designação de $C$. atra como espécie tipo por SANDHOUSE (1943), fechou por inteiro o significado do mesmo, criando uma situação estranha que agora procuro sanar com a designação de Centris dorsata Lepeletier, 1841, como espécie tipo.

O sentido continua sendo o corrente para Melanocentris Autorum, e assim vem sendo usado por SNELLING, que mais recentemente se ocupou do mesmo na revisāo dos Centridini Americanos (1974 e 1984: 23) e firmado por MICHENER (1951, 1954).

Quero anotar aqui, ainda que de passagem, que Ptilotopus ( 1 1 tï̀ pés plumosos) é masculino, e, caso o considerem como gênero, a concordância dos nomes adjetivos ou adjetivados das espécies, devem sofrer a acomodação, imitando a da espécie tipo: Ptilotopus americanus.

O exemplar que veio como Centris atra (lista de empréstimo: "537/3 Centris atra $=1$ Ex. (keine Typen), de S. Antônio, ColômBIA) se encaixa na chave apresentada por Friese para o 'subgênero' Cyanocentris (p.251), e entra bem na descrição de $C$. aeneipennis Mocsary, 1899, pelo carácter diagnóstico do clípeo: "clypeo laevi ac polito, lateribus sparsim punctato, apice truncato", e também na curta descrição de Friese (1900: 46): "clypeo glabro, nitidissimo". Realmente o clípeo tem toda a área média, estreitando-se até o bordo superior, largamente lisa, sem pontos, a não ser nos declives laterais ou um que outro ponto próximo ao declive. Ou como trás na descrição mais longa da fêmea: "Clypeus auf der Scheibe spiegelglatt, stark glänzend, nur an den Seiten mit einzelnen Punkten."

Isto nos leva ao seguinte posicionamento sistemático de algumas "espécies":

\section{Centris (Melacentris) aeneiventris Mocsary, 1899}

Centris aeneiventris Mocsary, 1899. Termész. Füz. 22: 252

Centris aeneiventris: Friese. 1900). Termész. Füz. 23: 46

Centris (Cvanocentris) aeneiventris: Friese, 1900. Ann. k.k. Naturhist. Hofmus.. Wien, 15 (3-4): 321.138 .

Centris (Melanocentris) atra Friese, 19(0). Ann. k.k. Naturhist. Hofmus., Wien, 15 (3-4): 267 (partim)

E aí já consta claramente ter o mesmo Friese visto material procedente do Brasil, da Bolívia (localidade do tipo), da Venezuela e da Colombia: "우 von Bogotá".

Digo partim ao citar atra para aí incluir o exemplar determinado por Friese de San Antonio, Colômbia. 


\section{Centris (Melacentris) braccata Packard, 1869}

Centris braccata Packard, 1869, 1st. Rep. Peabody Acad. Sci.: 57.

Centris xylocopoides Fox. 1899. Proc. Acad. Natur. Sci., Philadelphia: 69. Syn.n.

No Norte da America do Sul, acima do Amazonas, ocorre outra espécie com que $C$. (Ptilotopus) atra tem sido confundida, mas que pertence a Melacentris. É C. braccata Packard, 1869, de que diz o mesmo Friese nos comentários (p. 267): "Vielleicht ein unausgefärbtes Exemplar der atra?". C. braccata estende-se da Colômbia Amazônica à Trinidad estando representada na Coleção Moure (DZUP) por exemplares de Trinidad e do lado Norte da Amazônia. C. xylocopoides Fox, 1899, de Trinidad é um sinônimo de C. braccata. Vi os tipos de Packard e Fox. Pertence ao que agora chamo de Melacentris.

\section{Centris (Melacentris) intermixta Friese, 1900}

Centris ruficauda Friese. 19(0). Termész. Füz. 23: 47

Centris intermixta Friese, 1900. Termész. Füz. 23: 47

Centris ruficauda; Friese, 1900. Ann. k.k. Naturhist. Hofmus. 15 (3-4): 322.141.

Centris intermixta: Friese. 1900). Ann. k.k. Naturhist. Hofmus. 15 (3-4): 322.141.

Holótipo macho com as seguintes etiquetas: /Cauia/Matto Grosso Rhode/; a etiqueta de determinação: /Centris intermixta $\sigma^{\prime \prime}$ det. Friese 1898 n. sp./, e a etiqueta do Museu: /Zool. Mus./Berlin/. Em bom estado de preservação, faltando apenas todo o flagelo da antena direita.

Macho, moderadamente grande. Comprimento total aproximado $18,33 \mathrm{~mm}$, da asa anterior $16,7 \mathrm{~mm}$; largura da cabeça $6,3 \mathrm{~mm}$ e do segundo tergo $8,55 \mathrm{~mm}$.

Inteiramente preta com reflexos vagos verde-brônzeos em todo

quinto tergo e nas margens do segundo ao quarto; com as pernas, principalmente os fêmures, de um negro acastanhado. Amarelos: o labro marginado de preto em cima e aos lados e o plano elevado do clípeo formando uma mancha mais larga que longa (140: 100), com projeção média superior (até 120), deixando no bordo inferior estreita faixa escura e a porção superior em projeção mediana moderadamente larga, bilobada (40: 20). Tégulas pretas; asas bastante escuras, principalmente nas células radial e marginal; estigma e venação pretos.

A pilosidade bem desenvolvida cobrindo quase todo o tegumento, deixando o disco do clípeo glabro; predominantemente negro-murina, mais cinzenta nas genas e no disco médio do mesosterno, passando a amarelo-clara nos dois terços posteriores do mesoscuto, em todo o escutelo e axilas, com algumas reentrâncias finas de pilosidade escura ao longo da linha média e nos sulcos prescutais, parápsides e entre as tégulas e axilas; nos lados do quarto tergo e nos dois últimos segmentos abdominais.

A pontuação coberta pela pilosidade; no clípeo a parte média elevada vista em certa luz com rugas muito vagas, quase sem pontos, estes muito superficiais; nos declives com pontuação setígera moderadamente grossa, inclinada, os intervalos micro-reticulados pouco maiores que os pontos; na parte superior deprimido no meio, liso em direção à supraclipeal; nas paroculares os intervalos mais lisos; 
diante do ocelo médio uma pequena área lisa e também aos lados dos laterais, passando a muito fino-pontuada junto às órbitas.

Cabeça mais larga que longa; olhos grandes, pouco mais de duas vezes sua largura, esta duas vezes a largura das genas (440: 200: 120), muito convergentes para o vértice com a distância interorbital superior cerca de $3 / 7$ do comprimento do olho, e divergentes para baixo com a distância interorbital inferior 5/8 do comprimento do olho (188: 240: 280); área malar curta, cerca de meio diâmetro do flagelo (20). Clípeo 1,3 vezes mais largo que longo, porém 1,4 vezes mais longo que sua distância ao ocelo médio (200: 260: 140), com o disco bastante elevado sobre o plano da face, no meio ligeiramente rebaixado; com curta carena aguda acima do clípeo, coberta pela pilosidade; distância interalveolar superando dois diâmetros de alvéolo e a alveolorbital apenas chegando a meio diâmetro (94: 25: 120: d44); distância interocelar 1,5 vezes o diâmetro do ocelo médio, a ocelorbital reduzida a meio diâmetro e o vértice atrás dos ocelos cerca de dois diâmetros (75:25: 120: d50). As mandíbulas aparentemente tridentadas (não foram abertas); palpos maxilares de quatro artículos (20: 45: 30: 25); labro 1,3 vezes mais largo que longo. Escapo relativamente curto e grosso, pouco mais de duas vezes seu diâmetro, mais curto que a distância alveolocelar, menos de um sexto do flagelo e pedicelo juntos (100/45: 120: 625); fagelômero basal longo-pedunculado, três vezes seu diâmetro apical, o segundo bem mais curto que seu diâmetro, o terceiro tão longo como largo, ligeiramente mais curto que o quarto (125: 28: 40: 45: d40). Fêmures e tíbias posteriores inermes, quase de igual comprimento, pouco engrossados; basitarso dois terços do comprimento da tíbia, relativamente estreito. O último tergo com placa pigidial evidente com o bordo distal chanfrado em V aberto.

Friese faz aproximação entre esta espécie e Centris ruficauda e desta com Centris aeneiventris Mocsary, 1899.

Realmente $C$. ruficauda não difere de $C$. intermixta a não ser na coloração da pilosidade torácica, que é inteiramente preta. Há pequena diferença na configuração da mancha clipeal, parabolóide em ruficauda, a extremidade superior tocando a sutura epistomal, aparecendo melhor a depressão superior.

Esse tipo de variação de côr é bastante frequente em Melacentris com o mesonoto amarelo-piloso. Lembro como espécie parecida C. (Melacentris) obsoleta Lepeletier, 1841, havendo exemplares com o tórax inteiramente pretopiloso até amarelo-pálido-piloso, com todas as combinações imagináveis de pilosidade preta e amarela. O macho de $C$. obsoleta facilmente se separa desta espécie de Friese pelo clípeo preto, a pontuação muito mais densa nos lados, mais uniformemente abaulado, sem a depressão acentuada de intermixta/ruficauda. $C$. obsoleta sempre tem uma pequena mancha amarela na extremidade inferior das paroculares. Também a afastam dessas duas formas a presença de faixas cinzentopilosas marginais nos tergos, interrompida no segundo, completa no terceiro e seguintes.

É possível que essas duas 'espécies' sejam apenas variantes de cor na pilosidade. Não estou tão seguro quanto a $C$. pseudoephippia, que apesar de 
lembrar pelo nome a C. ephippia Smith, 1854, nada tem a ver com a mesma, sendo esta última integrante de Ptilocentris, conforme minhas notas de 1957, sobre o tipo conservado no The Natural History Museum, Londres.

$\mathrm{Na}$ sinonímia proposta dou preferência, como primeiro revisor, ao nome intermixta que melhor sintetiza a problemática nomenclatural.

AGRADECIMENTOS. Agradeço às autoridades do Museu de Berlim, Dr. Günther Peters. Jiretor, e Dr. Franz Koch, por proporcionarem-me a oportunidade de estudar esse material de importância fundamental na compreensão dos Apoideos Neotropicais.

\section{REFERÊNCIAS BIBLIOGRÁFICAS}

Brèthes, J. 1909. Hymenoptera paraguayensis. An. Mus. Nac. Buenos Ayres 19 (Ser. 3a., T. XII): 225-256.

Burmeister, H. 1876. Hymenopterologische Mittheilungen. Sttetiner Entomol.

Zeitgung 37 (4-6): 151-183

Fabricius, J.C. 1804. Systema Piezatorum. Brunswick, 439+30p.

FrIESE, H. 1898. Monographie der Bienengattungen Megacilissa, Caupolicana,

Diphaglossa und Oxaea. Ann. k.k. Naturhist. Hofmus., Wien, 13 (1): 322. 141.

1899. Monographie der Bienengattungen Exomalopsis, Ptilothrix, Melitoma und Tetrapedia. Ann. k.k. Naturhist. Hofmus., Wien, 14 (3): 247-304.

. 1899. Neue Arten der Bienengattungen Epicharis Klug und Centris Fabr. Termész. Füsetek, Budapest, 22: 39-48.

1900. Monographie der Bienengattung Centris (s. lat.) Ann. k.k. Naturhist. Hofmus., Wien, 15 (3-4): 237-350.

1904. Zur Synonymie der Apiden. (Hym.) Ztschr. f. syst. Hymenopt. Dipt. 4: 98-100.

KLUG, J.C.F. 1810. Einige neue Piezatengattungen. Magaz. Gesellsch.

Naturforsch. zu Berlin 4: 31-45.

Lepeletier de Saint-Fargeau, A. 1841. Histoire Naturelle des insectes Hyménoptères. Tome second, p.1-680.

Lepeletier de Saint-Fargeau, A. \& A. Serville. 1825-1828. Encyclopédie Méthodique, Histoire Naturelle. Tome II, p.792-800 (p. 1-344, 1825; p.345832,1828 ).

Michener, C.D. 1951. Subgeneric groups of Hemisia (Hymenoptera, Apoidea).

Jour. Kansas Entomol. Soc. 24: 1-11. 1954. Bees of Panamá. Bull. Amer. Mus. Nat. Hist. 104 (1): 1-176.

Michener, C.D. \& Jesus S. Moure. 1957. A study of the classfication of the more primitive non-parasitic Anthophorine Bees (Hymenoptera, Apoidea), Bull. Amer. Mus. Nat. Hist. 112 (5): 395-452.

Mocsáry, A. 1899. Species novae generis Centris Fabr. Termész. Füsetek, Budapest, 22: 251-255. 
Moure, J. 1945. Contribuição para o conhecimento dos Diphaglossinae, particularmente Ptiloglossa (Hym.-Apoidea). Arq. Mus. Parananese, Curitiba, 4: 137-178.

Schrottky, C. 1902. Les espèces des genres Megacilissa, Caupolicana, Oxaea, Epicharis, Centris, Meliphila and Euglossa dans la collection du Musée National de Buenos Aires. An. Mus. Nac. Buenos Aires 7: 317-327. 1902. Ensaio sôbre as abelhas solitárias do Brasil. Revta Mus. Paulista 5: $330-613$.

1903. Énumération des hyménoptèteres connus jusqu'ici de la République Argentine, de l'Uruguay et du Paraguay. An. Soc. Cient. Argentina 55: 80-91, 118-124, 176-186.

1904. Beitrag zur Kenntnis einiger südamerikanischen Hymenopteren. Allg. Ztschr. Entomol. 9: 344-349.

1907. Contribución al conocimiento de los himenópteros del Paraguay.-III. An. Cient. Paraguayos (7 Série I): 1-72.

SANDhousE, G.A. 1943 The type species of the genera and subgenera of bees. Proc. U.S. Nat. Mus. 92: 519-619.

SNElling, R.R. 1974. Notes on the distribution and taxonomy of some North American Bees o the genus Centris with description of new species (Hymenoptera: Anthophoridae). Contr. in Sci Los Angeles C. Mus. 259: $1-411$.

1984. Studies on the Taxonomy and Distribution of American Centridine Bees (Hymenoptera; Anthophoridae). Contr. in Sci. Los Angeles C. Mus. 347: 1-69. 